\title{
درجة فهم طلبة الكليات العلمية في جامعة اليرموك لعمليات العلم وممارستهم لها في ضوء بعض المتغيرات
}

\author{
ريمة عمر معتوق' ، عبد الله محمد خطايبة'، ابتسام قاسم ربابعةّج \\ 'باحثة في كلية التربية- قسم مناهج وطرق تدريس العلوم- جامعة اليرموك- الأردن

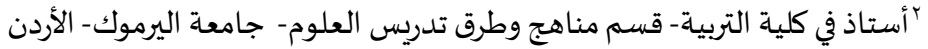 \\ "أستاذ مشارك في كلية التربية- قسم مناهج وطرق تدريس العلوم- جامعة اليرموك- الأردن
}

1Kulaep_hn@yahoo.com

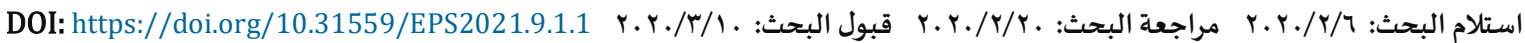

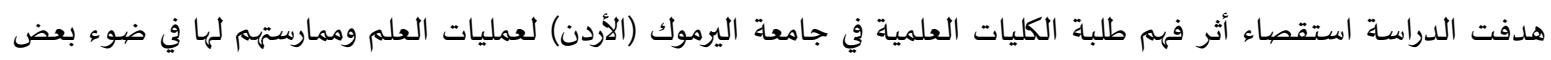

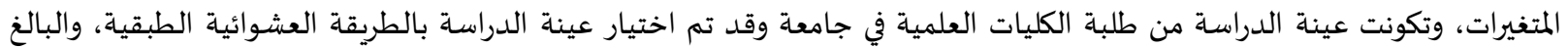

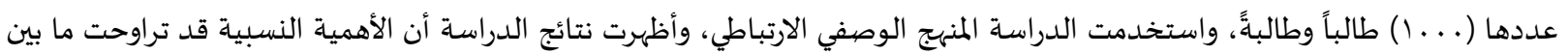
(9r\%-00\%)، كما أظهرت درجة مرتفعة لفهم عمليات العلم لدى الطلبة، وأظهرت وجود علاقة إيجابية دالة إحصائيًا بين فهم طلبة الكليات

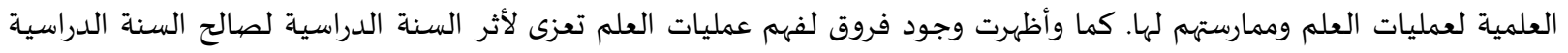

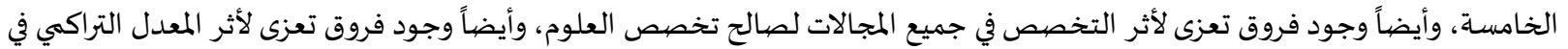

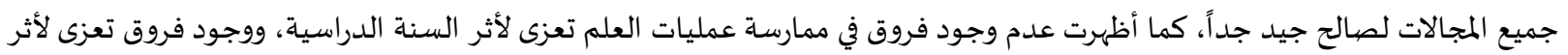
التخصص في جميع المجالات لصالح تخصص الصيدلة، وأيضاً وجود فروق تعزى لأثر المعدل التراكمي في جميع المجالات لصات لصالح المعدل التراكمي امتياز. وأوصت الدراسة الاهتمام بالناحية العملية جنباً إلى جنب مع الناحية المعرفية. كذلك فإن طلبة الماتية الكليات العلمية من خلال دراستهم الأكاديمية، يشاهد ويلتمس باستمرار المهارات العلمية من خلال ممارسة المنهج التجريبي والتحليل المنطقي، والتفكير العلمي وأيضياً من خلال استناده إلى الأدلة العلمية في تفسير النتائج.

الكلمات المفتاحية: جامعة اليرموك؛ طلبة الكليات العلمية؛ عمليات العلم؛ فهم وممارسة الطلبة.

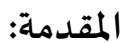

يشهد العصر الذي نعيشاه تطوراً ملحوظاً في المعرفة والتقدم العلمي مما نتج عنه كم هائل من المعلومات والمشكلات التي تواجه الفرد في حياته

اليومية.

وقد انعكست هذه التطورات المتسارعة على منظومة التربية من حيث سياستها وفلسفتها ومناهجها وأساليبها. مما أدى إلى جعل الأهداف التعليمياة القائمة على الحفظ واستظهار المعلومة ليست من الأهد اف القائمة لتدريس العلوم في القرن الحادي والعشرين؛ حيث أصبح الفهم والممارسة واكتساب مهارات عمليات العلم هي من أهم الأهد اف لتدرد العلوم، المعاهئ ونتيجة التطور الكبير للعلم ومستحدثاته، والتعقد المتزايد في العالم والبيئة من حول الإنسان، يصبح من الصعب عليه التعامل مع هذا العالم والتلاؤم معه بدون الحصول على أساسيات العلم والمعرفة واكتساب الأسلوب العلمي في 
ويؤكد كل من كارين وإيفانز على هذه النظرة (Carin \& Evans, 1980: 11) المتكاملة للعلم، ويشيران إلى أن للعلم ثلاثة مكونات أساسية تتكون

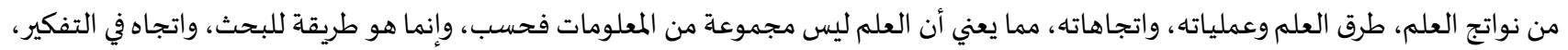

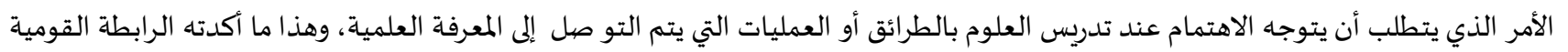

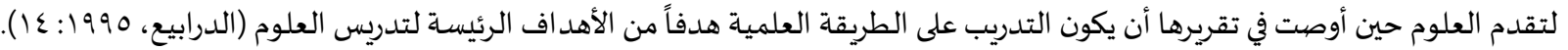

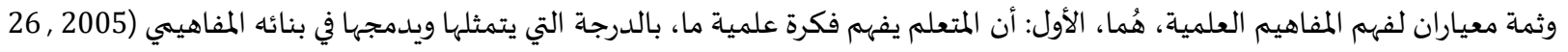

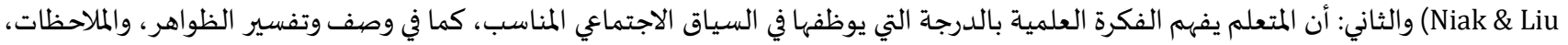
وتصميم الإجراءات العملية (Zeidler \& Sadler, 2005:32).

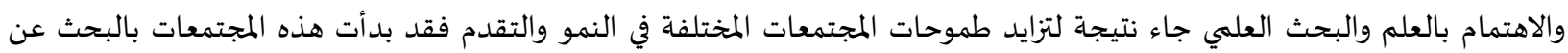

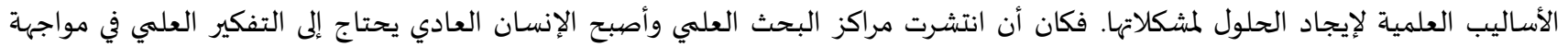

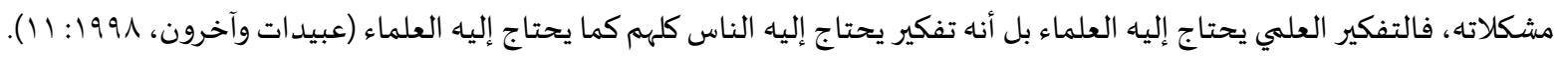

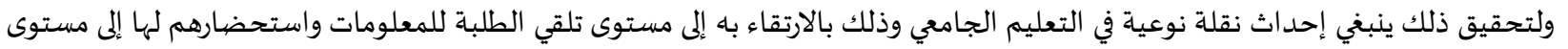

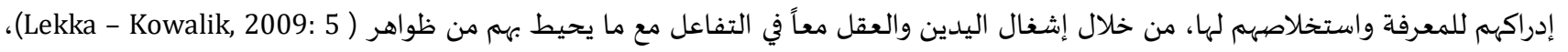

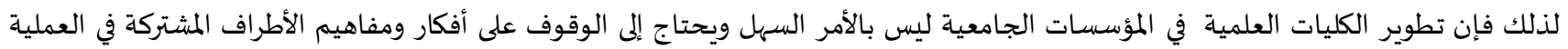

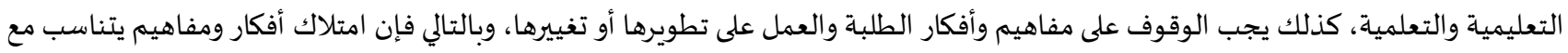
التطورات والإصلاحات الجديدة سيشكل أساساً صلباً لأي مجهود تطوري لكلياتهم، وفي المقابل فإن المفاهيم التقليدية ستشكل عائقاً أمام هذها الجهود) (Northcote, 2005: 41).

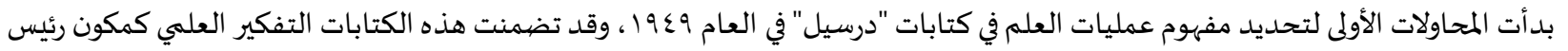

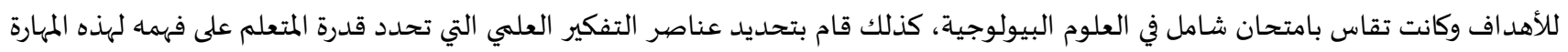

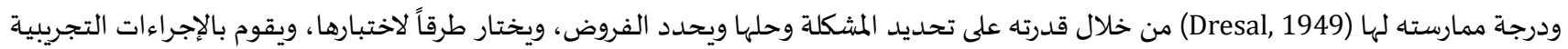
ويقومها تقويم الناقد.

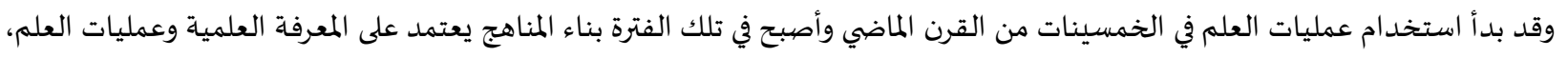

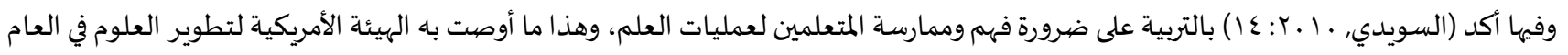

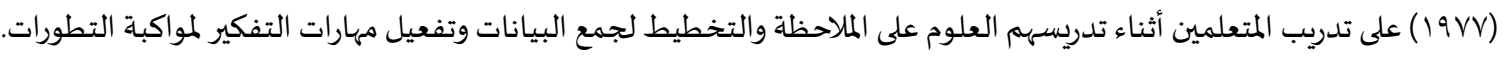

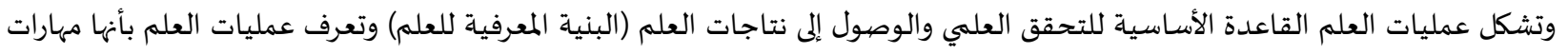

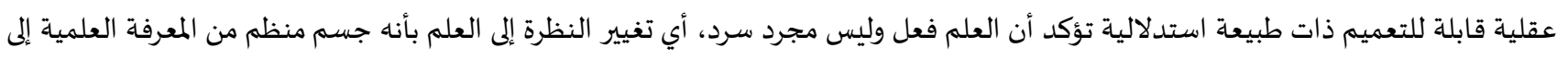

العلم كعملية (علي، 9. . ب: rا).

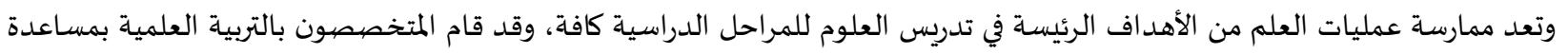

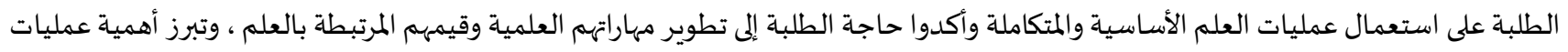

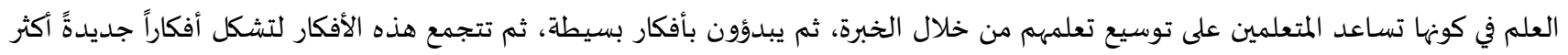

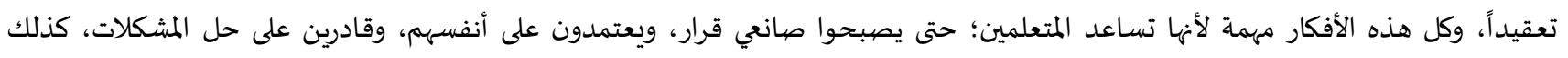

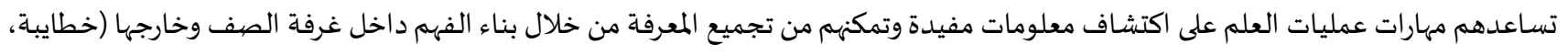

(Y ( 2011

اكتساب الطلبة لعمليات العلم يجب أن تكون هدفاً رئيساً لتدريس التربية التكنولوجية. ويشير الخليلي وحيدر ويونس (1997) إلى أن عمليات

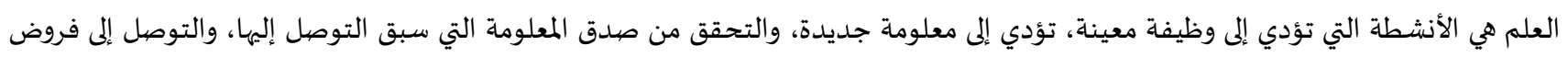

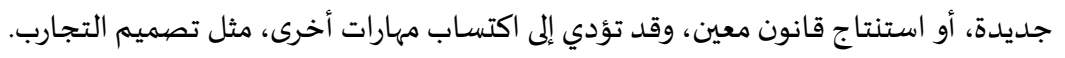

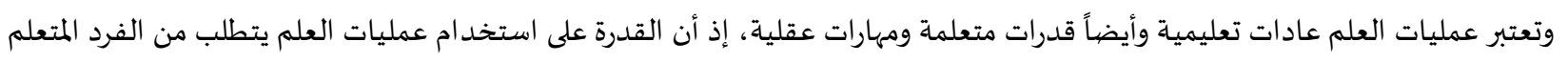

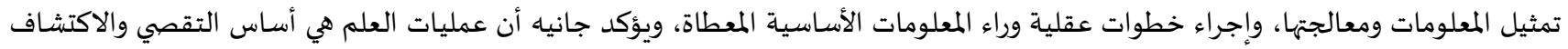

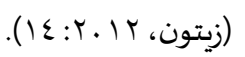

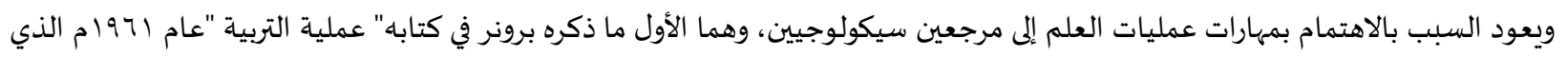

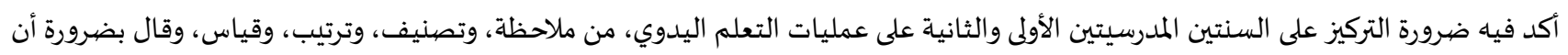

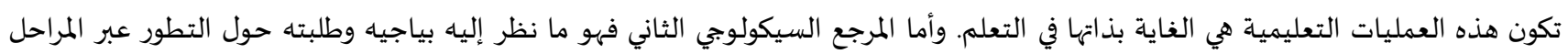


الدراسية، وأن الأطفال يتقدمون في نموهم المعرفي عبر أربع مراحل وهي: المرحلة الحس حركية، ومرحلة ما قبل العمليات، ومرحلة العمليات المادية،

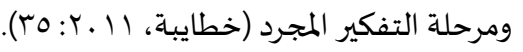

وقد ظهر العديد من التصنيفات لعمليات العلم، أهمها تصنيف المنظمة الأمريكية لتقدم العلوم AAAS)1997 American Association for حيث قسمت عمليات العلم إلى قسمين، وهما عمليات العلم الأساسية، وهي: الملاحظة، والتصنيف، والقياس،

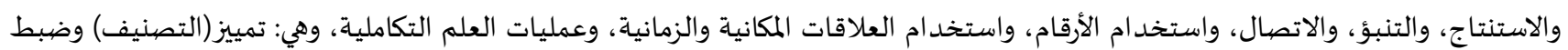

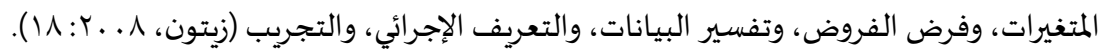

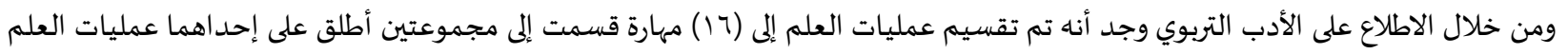

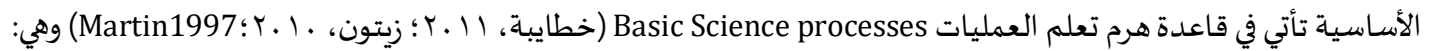

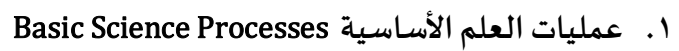

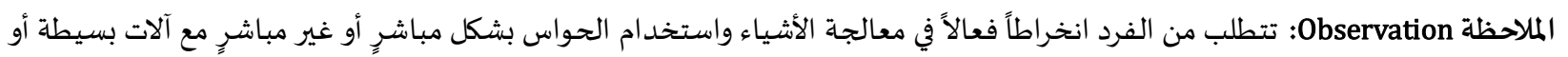
معقدة وتصف هذه العملية صفات الأشياء والتغيرات بدلالة الأفعال والنماذج والعلاقات، و فيها يتم ملاحظة ومشاهدة الصفيات التهات الظاهرية

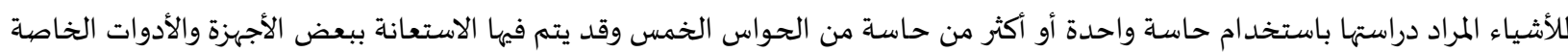
بعملية الملاحظة وتسجيل الأحداث بالملاحظة المباشرة. القياس Measuring: وهو أن تصف الحدث باستخدام الأدوات لتعيين الملاحظات كمياً. ويستخدم للقياس أدوات غير معيارية مثل الأيدي

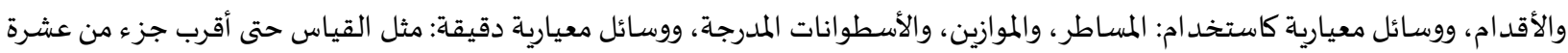

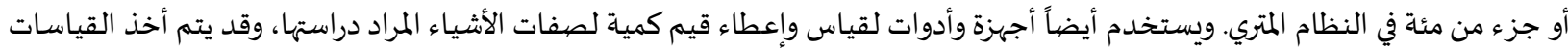

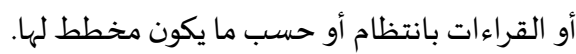
التصنيف Classifying: ترتيب للمعلومات بناءً على العلاقات التي يمكن ملاحظتها. ويتم في هذه العملية خلق مجموعات باستخدام صفة واحدة،

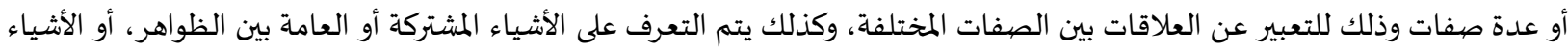

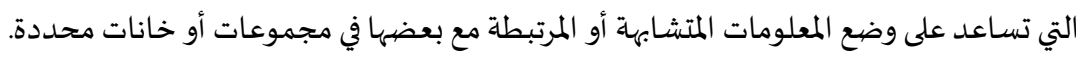
الاستنتاج (الاستنباط) Deducting: وفيه يتم الوصول إلى النتائج على أساس من الأدلة والحقائق والملاحظات، فالاستنتاج عملية عقلية يتم فيها تفسير وتوضيح الملاحظات وتعتمد على المعارف السابقة ويظهر الفرد القدرة على شرح، أو تفسير الملاحظات التي يلاحظها بناء على خبراته السابقة أو يتم التوصل إلى التعميمات وفهم العلاقات بين الظواهر والأحداث ويتم تطبيق النتائج التي تم استنتاجها في مواقف أخرى ألمات الاستقراء Inducting : و يتم فيها الانتقال من الخاص إلى العام ومن الجزء إلى الكل، بمناقشـة الطلبة في حقائق علمياة، تقودهم إلى استنتاج

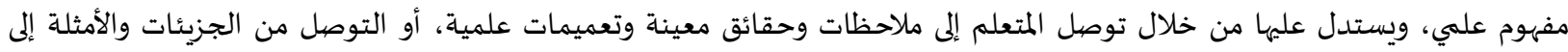
العموميات. الاستدلال Inferring : وفيه يتم تقديم الشروحات أو أسباب الأحداث على أساس حقائق محدودة، ومصداقية الاستدلالات تعتمد بشكل كبير

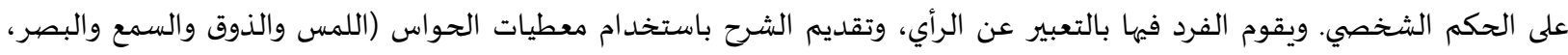
والشم)، شرح العلاقات السببية. التنبؤ Predicting: توقع للأحداث والعلاقات المستقبلية (الأسباب والنتائج) من خلال معالجة الأشياء من خلال الخبرات والملاحظات السابقة،

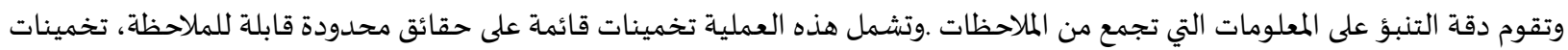
قائمة على فهم دقيق لعلاقات السبب والنتيجة. استخدام الأرقام Number Using : هذه المهارة تعتمد على توظيفها للعلاقات الكمية وهذا يعطيها صففة المهارة الرياضية، وفيها يكون التعبير عن الأفكار والملاحظات والعلاقات بواسطة الأرقام أكثر من الكلمات، وذلك من خلال إجراء العمليات الحسابية لمعالجة البيانات واستخدام القوانين الرياضية والعلاقات العددية بين المفاهيم العلمية. استخدام العلاقات المكانية الزمانية Using space-Time Relation ship: هو تصور أو تخيل للأحداث، ويتم التعامل مع الأشياء من حيث أشكالها وقت ملاحظتها وقربها أو بعدها وحركتها وسرعتها، وهي بذلك تسهل عملية التعرف على الأشكال والمواقع. الاتصال (التواصل) Communicating: نقل نتائج الدراسات والمعلومات التي تم التوصل إليها، إلى الآخرين عن طريق وسائل الاتصال المختلفة مثل استخد ام الكلمات المنطوقة والمكتوبة، واستخدام الرسوم التوضيحية والرسوم البيانية والمعادلات الرياضياة. Y. عمليات العلم التكاملية Processes Science Integrated: وهي ست عمليات علمية متقدمة، وهي أعلى مستوى من عمليات العلم الأساسية أي أنها تكون في هرم تعلم مهارات العمليات العلمية، وهي: 
تفسير البيانات Interpreting data: هي قدرة الطالب على تفسير وصياغة الأفكار من خلال نتائج التجريب التي توصل إلهها بأسلوبه الخاص، وكذلك يقوم بتفسير البيانات التي توصل إلها بطريقة غير مباشرة، وتبدو هذه العملية واضحة عند استخدام الجداول والرسوم البيانية لتوضيح و تفسير البيانات والإجابة عن الأسئلة المطروحة.

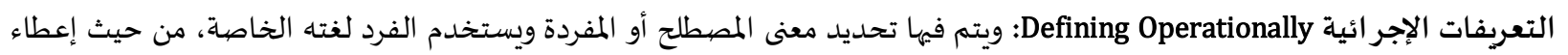
تعريف للأشياء أو الظواهر معلومات كافية عن ما سيقوم باه، أو يلاحظه فيما يتعلق بالظواهر والأشياء حولهـ. ضبط المتغيرات Controlling variables: وهي تحديد المتغيرات المستقلة والتابعة، وكذلك الربط بين المتغير المستقل والتابع، من أجل تنفيذ استقصياء مقترح. وضيع الفرضيات Hypothesizing: فرض ملاحظات أو استنتاجات تكون قابلة للاختبار، والفرض قدرة عقلية يمكن من خلالها أن يقدم الفرد أدلة قابلة للتفسير. تصيميم التجريب Designing Experiments: هي تمكن الفرد من القيام بتجارب علمية بنجاح ويتم ذلك من خلال: جمع المعلومات واختبار الأسئلة والفرضيات وقدرته على ضبط المتغيرات وكذلك تمكنه من استخدام خطط منظمة في خطوات متتالية حتى يتم اختبار الفرضية وتفسير ومناقشة النتائج بعبارات قابلة للقياس. صياغة النماذج Formulation Models : وتكون عبارة عن وصف وبناء للتفسيرات الرياضية أو الفيزيائية أو الكلامية كذلك وصف وبناء للأنظمة والظواهر التي لا يمكن اكتشافها أو ملاحظتها بصورة مباشرة ويتم تمثيل العالم الواقعي باستخدام نماذج ذهنية يتم من خلا لها فهم الظاهرة.

الدراسات السابقة: تم الاطلاع على العديد من الدراسات العربية والأجنبية التي تناولت موضهوع عمليات العلم من عدة زوايا، وفي حصر الباحثون للدراسـات السابقة

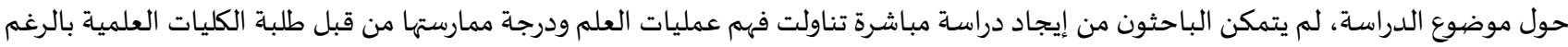

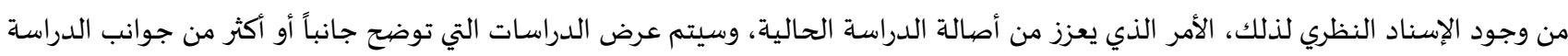
الحالية مرتبة من الأقدم إلى الأحدث. فقد أجرى خطايبة وبعارة (r . . Y) دراسة للتعرف على مدى فهم طلبة الكيمياء في كليات العلوم في الجامعات الأردنية الرسمية لمهارات عمليات

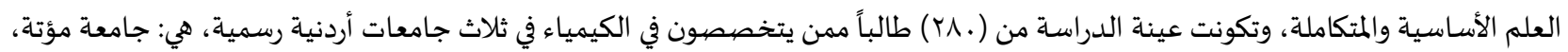

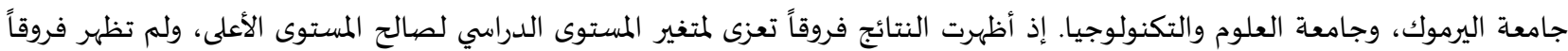

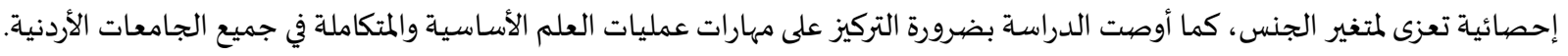
أما دراسـة عطية والحدابي (r . . ) فقد هدفت لقياس مستوى عمليات العلم التكاملية لدى طلبة الأقسام العلمية بكلية التربية - جامعة

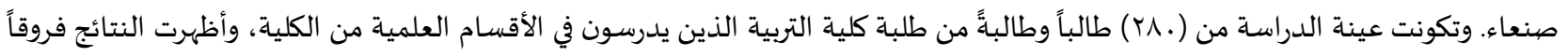
في أداء الطلبة تبعاً لسنوات الدراسـة الجامعية، ولصالح المستوى الأعلى، ولم تجد فروقاً تُعزى إلى الجنس. وأجرى كلاً من أكا وجوفين و أيدوجدو (Aka \& Guven \& Aydogdu , 2010) دراسة هدفت التعرف على أثر طريقة حل المشكلات على عمليات

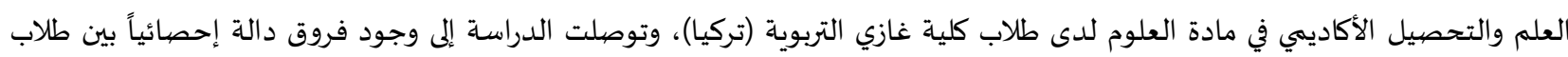
المجموعة التجريبية وطلاب المجموعة الضيابطة في التطبيق البعدي لاختبار عمليات العلم واختبار التحصيل الأكاديمي لصالح المجموعة التجريبية. وأما كارا مصطفى اوجلو (karamustafaoglu, 2011) فقد هدفت إلى تحديد مستوى عمليات العلم لدى طلبة كلية العلوم والتكنولوجيا، وقد ضيمت الدراسة (.ع) طالباً وطالبةً من الملتحقين في جامعة أماسيا (Amasya) في تركيا، وقد طُبق اختبار عمليات العلم قبل التحاقهم وبعده في هذه المساقات. بينت نتائج الدراسة أن هناك العديد من المشكلات التي يعاني منها هؤلاء الطلبة في فهم عمليات العلم، وخاصة عمليات العلم التكاملية قبل انتظامههم في هذه المساقات، وتقلصت هذه المشكلات إلى حد كبير بعد دراستهم لتلك المساقات وأجرى أيدوجدو وإيركلو و إيرتين (Aydogdu, Erkol, \& Erten, 2014) دراسة هدفت التعرف على مهارات عمليات العلم الأسـاسية والمتكاملة لدى معلمي المدارس الابتدائية وفقًا لبعض وإئردين المتغيرات بالإضافة إلى نتائج أخرى تم الاستنتاج أن مهارات عمليات العلم الأساسية لمعلمي المدارس

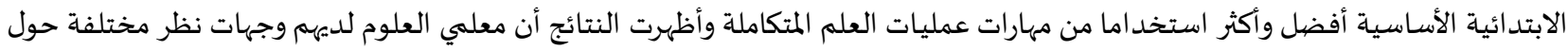
أهمية تلك المهارات ويتحدثون عن بعض المهارات الأساسية والمهارات العامة.

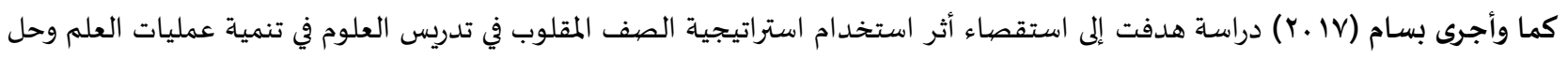

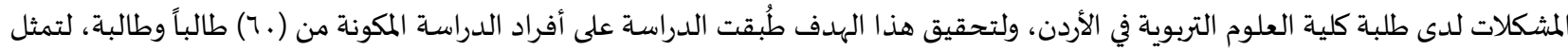


إحداها المجموعة التجريبية وعددها ( •r) طالباً وطالبةً درست باستخدام استراتيجية الصف المقلوب، والأخرى ضابطة وعددها (.ب) طالباً وطالبة

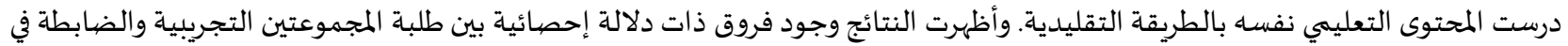

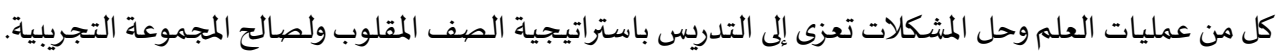
يتبين مما سبق ومن مرا جعة الإطار النظري والدراسـات السابقة ذات الصلة، أن هناك ضيعف في فهم الطلبة والمعلمين لعمليات العلم الأساسية والمتكاملة، ومدى أهمية امتلاك الطلبة عمليات العلم الأساسية والمتكاملة وتأثيرها على تحصيلهم الدراسي والسلوك الإيجابي والدافعية وجوانب أخرى النيات لديهم. وتتميز هذه الدراسـة عن الدراسات السابقة في أنه تم تطبيقها على مجتمع الجامعات، وهي من أوائل الدراسات العربية التي درست هذا الدا البعد في

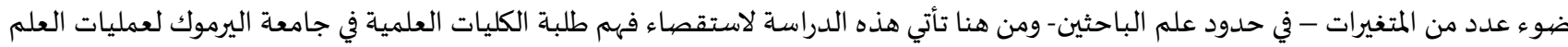

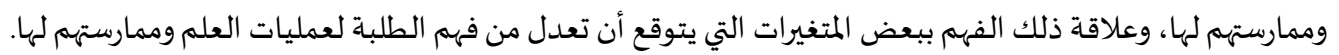

مشكلة الدراسـة وأسئلتها:

يعتبر تمكن الطلبة من مهارات عمليات العلم سواء الأساسية أو التكاملية في جميع مراحل التعليم الأساسي والجامعي يدل على تقدم الأنظمة التربوية وإنجازاتها، وهذا يتطلب من الكادر التدريسي تبني استراتيجيات تدريسية متنوعة تُسهم في اكتساب الطلبة لعمات لعمليات العلم الأساسية والتكاملية، وتنميتها وتحسينها، وتوظيفها في حياتهم العلمية والعملية.

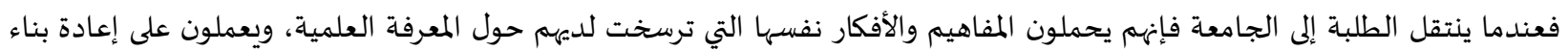
معاني جديدة عن العلم والمعرفة العلمية، فيعملوا على تطوير ثقافتهم العلمية، ونظراً لأهمية هذه العناصر في حياة المتعلمين، فإن الجهان الجهود تبذل دوماءمن أجل إعداد خطط مناسبة لهمه. لذا يتطلب من طلبة الكليات العلمية ومعلمي المستقبل وأطباء المستقبل أن يمتلكوا المعرفة العلمية ذات اتهبة العلاقة بعمليات العلم الأساسية والتكاملية، وممارستهم لها لا سيما وأن هذا النوع من المعارف يؤثر على قراراته في اختيار المهنة المناسبة له، كما يؤثر على ممارساته في المهنة التي لمهي

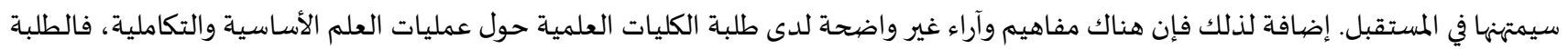
بحاجة إلى أن يدرسوا قضايا الأحداث الجارية المُختلف عليها، وأن يحلوا المشكلات، وينظموا المعلومات، ويميزوا بين الحقائق والآراء، ويدرسوا وجهات النظر المختلفة، الأمر الذي يتطلب التدريب المستمر وتغيير مفاهيم الطلبة نحو فههم وممارسة أكثر لعمليات العلم.

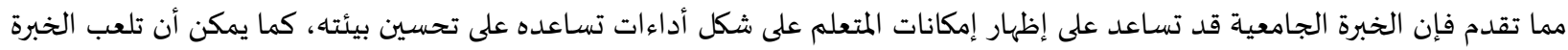
الجامعية أثراً كبيراً في عمليات العلم عند طلبة الجامعة سواء كان ذلك الجعاء عن طريق مساقات جامعية وأنشطة ومناخ جامعي، وقد تؤثر في المهارات العلمية

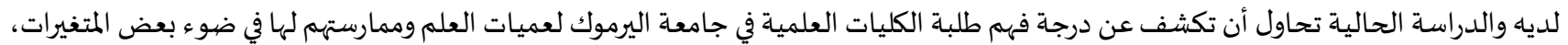
وبشكل أكثر تحديداً تحاول الدراسة الإجابة عن الأسئلة الآتية:

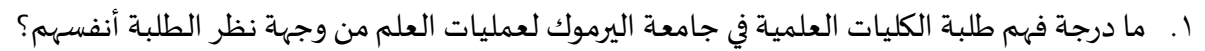
r. ما درجة ممارسة طلبة الكليات العلمياة في جامعة اليرموك لعمليات العلم من وجهاة نظر الطلبة أنفسهم؟

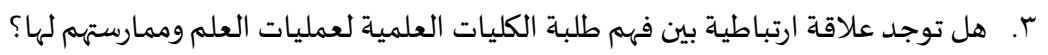

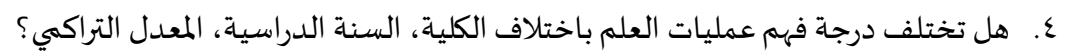

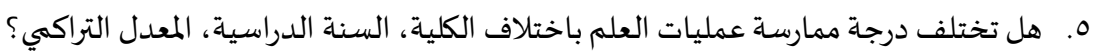

أهمية الدراسـة: يتوقع من الدراسة أن تفيد في الجانبين النظري والعملي.

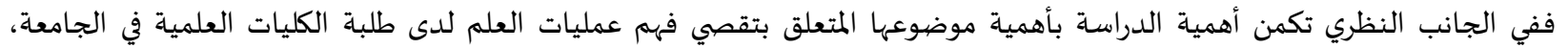

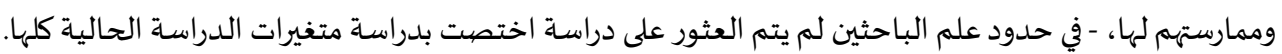
وفي الجانب العملي تكمن أهمية الدراسة بأن تكون مرشدا للكليات العلمية في تضمين برامجها مواد علمية متعلقة بعمليات العلم الأساسية

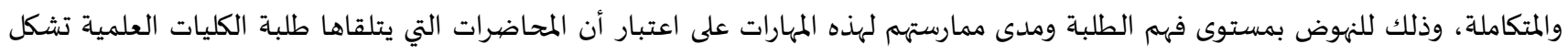

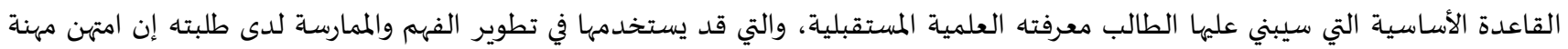
التدريس، ومن المؤمل أن تحقق هذه الدراسة إسهامات واضحة في الثقافة العلمية لدى الطلبة مما يجعلهم جاهزين لدخول سوق الديه العمل بكفاءة عالية،

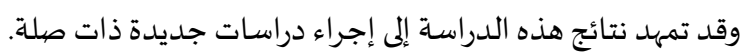


حدود ومححددات اللدراسة:

ستحدد تعميم نتائج الدراسة في ضوء المحدددات المدات التالية:

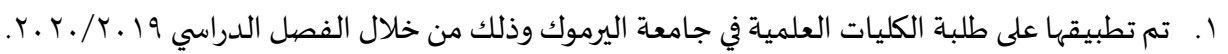

r. دقة إجابات الطلبة على أدوات الدراسة المستخدمة.

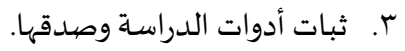

المصطلحات الإجر ائية:

عمليات العلم: Science Process : هي مجموعة من القدرات والعمليات العقلية اللازمة لتطبيق طرق العلم والتفكير العلهي بشكل صحيح (زيتون،

. (V:T. . .

ويعرفها الباحثين إجر ائياً: هي مجموعة من العمليات الأساسية، يمارسها طلبة الكليات العلمية، على شكل نشاط عقلي وفقاً للمنهجية العلمية عند

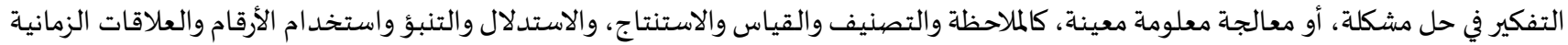

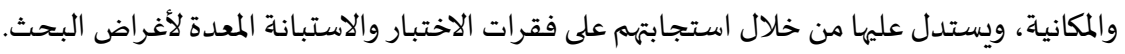
طلبة الكليات العلمية Students of scientific colleges : هم طلبة الكليات العلمية في جامعة اليرموك المنتظمون في الدراسة، وضئه وضمن أقسام مختلفة هي: (الطب، الهندسة، الصيدلة، العلوم) للسنوات الثانية والثالثة والرابعة والخامسة ممن هم على مقاعد الدراسة في الفصل الدراسي الأول من العام

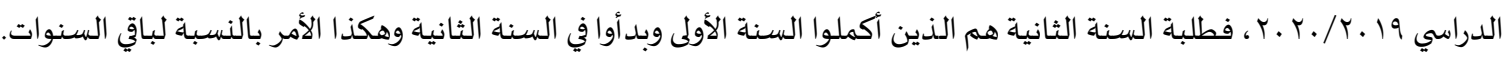

منهج الدراسة والمعالجة الإحصائية: سيتم استخدام التصميم الوصفي/ المستي، بقصداجه تجميع البيانات ومن ثم استخلاص النتائج، ولتحليل النتائج تم استخدام البرنامج الإحصائي لإجراء التحليلات الوصفية والاستدلالية، وتمثلت هذه التحليلات باستخراج المتوسطات الحسابية والانحرافات المعيارية لأداء عينة الدراسة

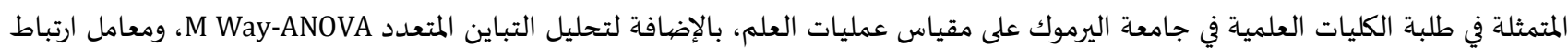
بيرسون لمعرفة العلاقة الارتباطية بين المتغيرات.

مجتمع الدراسة وعينتها: تكوّن مجتمع الدراسة من جميع طلبة الكليات العلمية في جامعة اليرموك في المتغيرات: التخصص الأكاديمي، والسنة الدراسية، والمعدل التراكمي

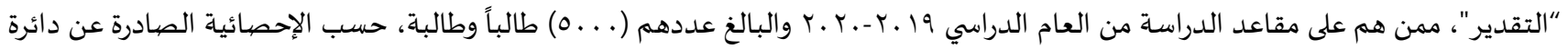
القبول والتسجيل في الجامعة، أما عينة الدراسة فقد بلغ عددهم ( . . 1) طالباً وطالبة، تم اختيارهم بالطريقة العشوائية الطبقية، والجدول (1) يبين

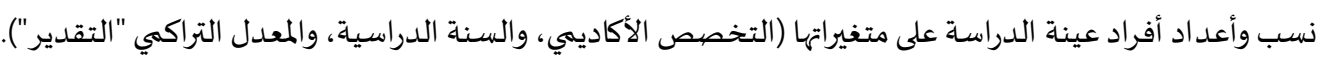
جدول (1): التكرارات والنسب المئوية حسب السنة الدراسية والتخصص والمعدل التر اكمي

\begin{tabular}{|c|c|c|c|}
\hline النسبة المئوية\% & التكرار & الفئات & \\
\hline$\% 10, r$ & $10 r$ & سنة ثانية & السنة الدراسية \\
\hline$\% \Upsilon \Upsilon 9,9$ & rq9 & سنة ثالثة & \\
\hline$\%$ \% & $r \Lambda$. & سنة رابعة & \\
\hline$\% \Upsilon \Upsilon 7, \Lambda$ & $r 71$ & سنة خامسة & \\
\hline$\% 1 Y, \Lambda$ & $1 \mathrm{VA}$ & طب & التخصص \\
\hline$\% \varepsilon V, \varepsilon$ & $\varepsilon \vee \varepsilon$ & هندسة & \\
\hline$\% 10, r$ & 104 & صيدلة & \\
\hline$\% 19,7$ & 197 & علوم & \\
\hline$\% 01,9$ & 019 & جيد فما دون & المعدل التراكمي "التقدير" \\
\hline$\%$ & ri. & جيد جداً & \\
\hline$\% 1 Y, 1$ & $|V|$ & ممتاز & \\
\hline$\%$ & $1 \ldots$ & المجموع & \\
\hline
\end{tabular}

أداتا الدراسـة: أولاً: أداة فههم عمليات العلم إدراسه قام الباحثون ببناء اختبار فهم عمليات العلم، بعد العودة لعدد من الدراسات والأبحاث ومشاريع إصلاح العلوم (رواشدة والخطايبة، 199 أبهات ؛

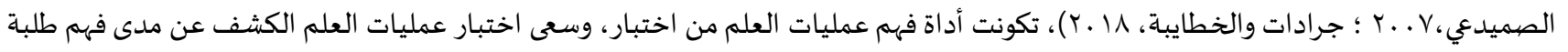


الكليات العلمية لعمليات العلم الأساسية والمتكاملة وتكون الاختبار من (ع) (V) فقرة تدل على مهارات عمليات العلم وقد توزعت فقرات الاختبار على (V) أبعاد هي: الملاحظة، القياس، الاستنتاج، الاستدلال ,التنبؤ، استخدام العلاقات المكانية والزمانية ، الاتصنال.

صيدق الاختبار:

وقد تم التحقق من صدق محتوى أداة الدراسة من خلال عرضها على لجنة تحكيم من التربويين المتخصصين في مناهج العلوم وطرائق تدريسها،

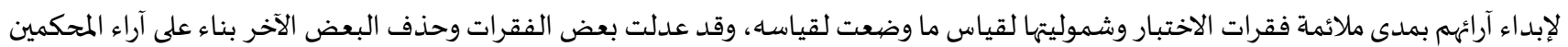

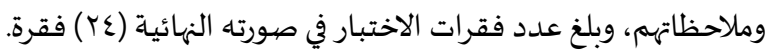

ثبات الاختبار:

للتأكد من ثبات أداة الدراسة، فقد تم التحقق بطريقة الاختبار وإعادة الاختبار (test-retest) بتطبيق الاختبار، وإعادة تطبيقه بعد أسبوعين

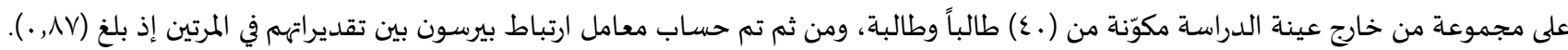

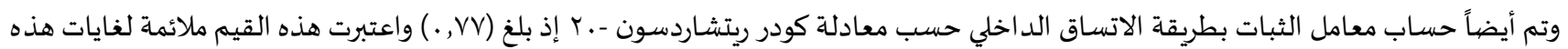
الدراسـة.

معامل الصعوبة والتميز:

تم استقصاء معاملات الصعوبة لاختبار عمليات العلم من خلال تطبيقه على عينة استطلاعية مكونة من (.ع) طالباً وطالبة من خارج عينة

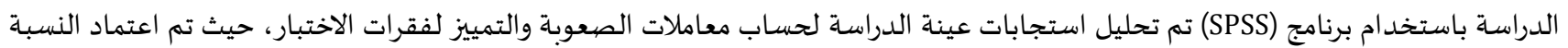
المئوية للطلبة الذين أجابوا عن الفقرة إجابة خاطئة كمعامل صعوبة لكل فقرة من فقرات الاختبار، بينما حسب معامل التمييز لكل فقرة معامل

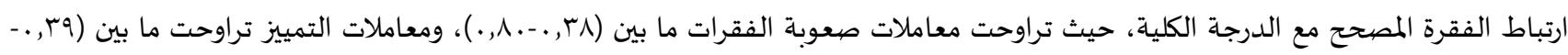
117 . •). وعلياه فلم يتم حذف أي من الفقرات بناء على معامل الصعوبة أو معامل التمييز.

ثانياً: أداة ممارسة عمليات العلم

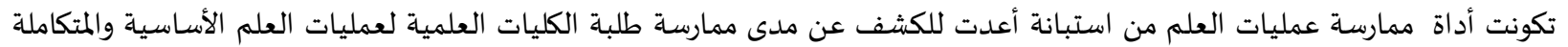
وتكونت الاستبانة من (.r) فقرة تدل على مهارات عمليات العلم, تضمنت الاستبانة عمليات العلم التي تم اختيارها في الاختبار الذي يقيس فهم طلبة التهات

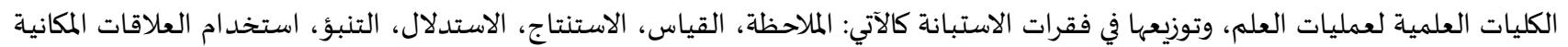
والزمانياة، الاتصال.

صدق محتوى أداة ممارسة عمليات العلم الأساسية والمتكاملة: للتحقق من الصدق الظاهري للاستبانة تم عرضها على مجموعة من المحكمين من أساتذة تربويين في جامعة اليرموك، ومشرفين في وزارة التربية والتعليم من ذوي تخصص مناهج العلوم وأساليب التدريس وتخصص القياس والتقويم، وطلب من المحكمين الحكم على جودة الاستبانة في ضوضو شموليتها لعمليات العلم، والصحة اللغوية، والعلمية لفقرات الاستبانة، ودرجة ارتباط الفقرات بالعمليات المراد قياسها ومناسبة البدائل للفقرات

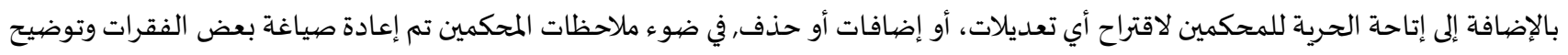

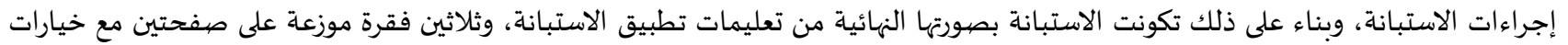

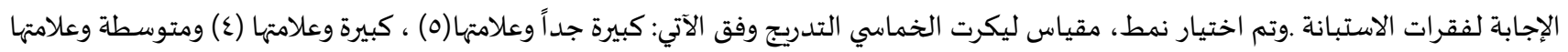

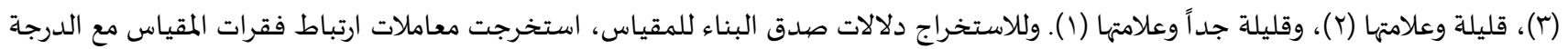

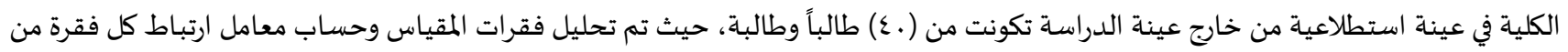

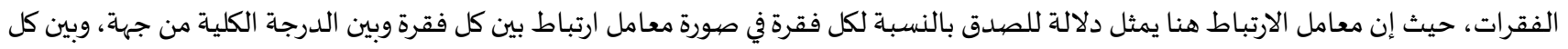

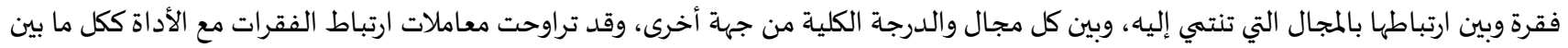

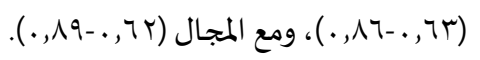

ثبات أداة ممارسة عمليات العلم الأسـاسية والمتكاملة للتأكد من ثبات أداة الدراسة، فقد تم التحقق بطريقة الاختبار وإعادة الاختبار (test-retest) بتطبيق المقياس، وإعادة تطبيقه بعد أسبوعين على مجموعة من خارج عينة الدراسة مكوّنة من (.ع) طالباً وطالبة، ومن ثم تم حساب معامل ارتباط بيرسون بين تقديراتهم في المرتين حيث تراوحت

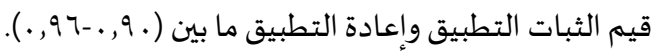

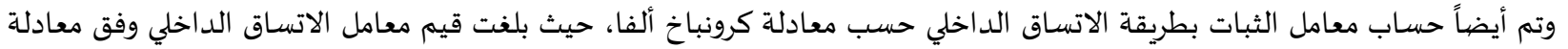

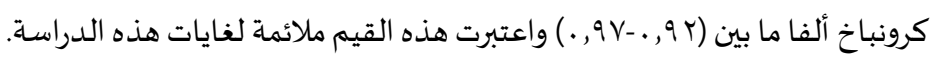


متغيرات الدراسـة:

اشتملت الدراسة على المتغيرات الآتية:

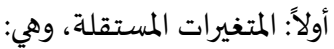

1. الجنس (النوع الاجتماعي) وله فئتان: ذكور وإناث.

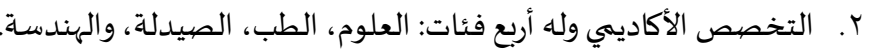

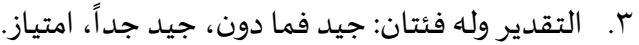

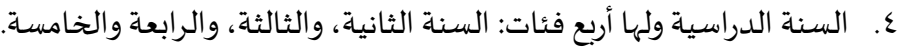

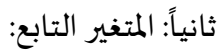

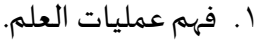

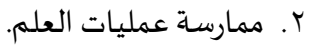

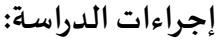

تم اتباع الإجراءات الآتية في تنفيذ الدراسـة.

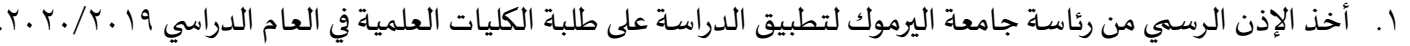

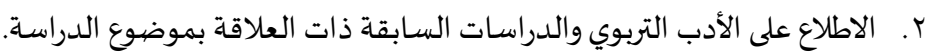

ك. إعداد أداتي الدراسة وهما اختبار فهم عمليات العلم، واستبانة ممارسة عمليات العلم، وتم التحقق من صهدقه وثباته.

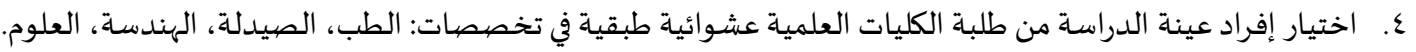
0. تحليل النتائج باستخدام برمجية(spss)، ومناقشا النتائج وتفسيرها والتوصل إلى التوصيات.

نتائج الدراسة ومناقشتها:

بعد تطبيق إجراءات الدراسـة، وإجراء التحليلات الإحصائية الوصفية والاستدلالية المناسبة، تم الحصبول على النتائج التالية: أولاً: النتائج المتعلقة بالسؤال الأول ومناقشته وهو: ما درجة فهم طلبة الكليات العلمية في جامعة اليرموك لعمليات العلم الأساسية والمتكاملة من

وجهة نظر الطلبة أنفسهه؟

للإجابة عن هذا السؤال تم استخراج الأهمية النسبية لدرجة فهم طلبة الكليات العلمية بجامعة اليرموك لعمليات العلم الأساسية والمتكاملة،

والجدول أدناه يوضح ذلك.

جدول (r): المتوسطات الحسابية والانحر افات المعيارية لعمليات العلم مرتبة تنازلياً حسب الأهمية النسبية

\begin{tabular}{|c|c|c|c|c|c|}
\hline المئوية\% & المعياري & المستوسطي & المججال & الرقم & الرتبة \\
\hline \% & $r, \varepsilon r q$ & 0,01 & عمليات العلم الأساسية & 1 & 1 \\
\hline$\%$ & 1, rی. & $r, 74$ & عمليات العلم المتكاملة & r & r \\
\hline$\%$ & $r, 1 \% 7$ & $\lambda, 1 T$ & اختبارعمليات العلم & & \\
\hline
\end{tabular}

يبين الجدول (ץ) أن الأهمية النسبية قد تراوحت بين (جץ\%-9٪/)، حيث جاءت عمليات العلم الأساسية - اختبار في المرتبة الأولى بأعلى أهمية نسبية بلغت (9 (\%)، بينما جاءت عمليات العلم المتكاملة - اختبار في المرتبة الأخيرة وبأهمية نسبية بلغت (جr/)، وبلغت الأهمية النسبية لاختبار

عمليات العلم ككل (عَ/).

جدول (r): المتوسطات الحسابية والانحر افات المعيارية لعمليات العلم الأساسية والمتكاملة مرتبة تنازلياً حسب الأهمية النسبية

\begin{tabular}{|c|c|c|c|c|c|}
\hline الأهمية النسبية\%\% & الانحراف المعياري & المتوسط الحسابي & المجال & الرقم & 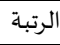 \\
\hline$\%$ & ( & $1,1$. & القياس & $r$ & 1 \\
\hline$\%$ \% & . VTr & $1, .0$ & الاستنتاج & $r$ & $r$ \\
\hline$\%$ &., 771 & . AT & الملاحظة & 1 & $r$ \\
\hline$\%$ & . &.,$V T$ & استخدام العلاقات المكانية والزمانية & 7 & $\varepsilon$ \\
\hline 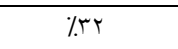 &.,$T V r$ & . & الاستدلال & $\varepsilon$ & 0 \\
\hline$\%$ &.,$T \sum \lambda$ &., 09 & 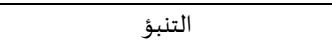 & 0 & 7 \\
\hline$\%$ &., 011 &., 01 & الاتصال & $\mathrm{v}$ & $\mathrm{v}$ \\
\hline$\%$ & $r, \varepsilon r q$ & 0,01 & م الأسساسية والمتكاملة & & \\
\hline
\end{tabular}


يبين الجدول (r) أن الأهمية النسبية قد تراوحت ما بين (9\%٪-00\%)، حيث جاء القياس في المرتبة الأولى بأعلى أهمية نسبية بلغت (00\%)، بينما

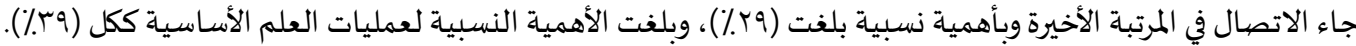

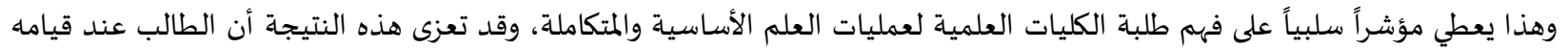
بعملية القياس يقوم باستخدام الأدوات لتعيين ملاحظاته كمياً، وأيضاً يستخدم أدوات غير معيارية للقياس مثل الأيدي والأقدام، كذلك استخدامهيم

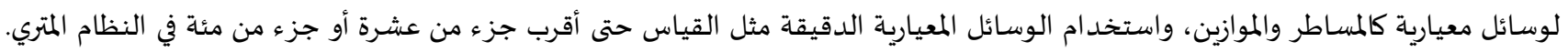

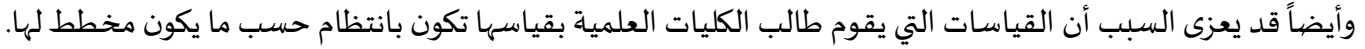

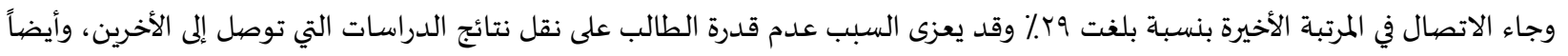

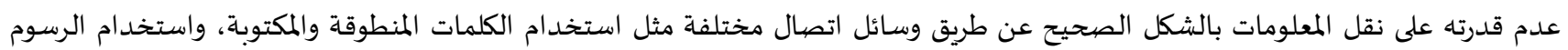

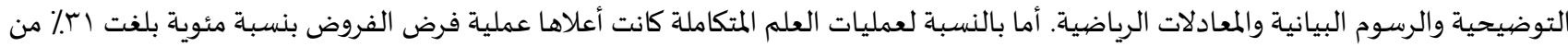

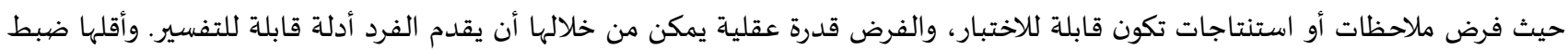

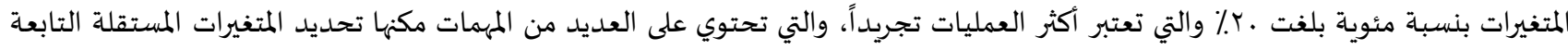
والربط بينهما. وقد اتفقت نتيجة هذه الدراسة مع دراسة كارامصطفى أوجلوا (1) ـ (1) التي أظهرت نتائجها أن هناك العديد من المشكلات التي يعاني منها هؤلاء الطلبة في فهم عمليات العلم وخاصة عمليات العلم التكاملية.

السؤال الثاني: ما درجة ممارسة طلبة الكليات العلمية بجامعة اليرموك لعمليات العلم الأسساسية والمتكاملة من وجهة نظر الطلبة أنفسهم؟

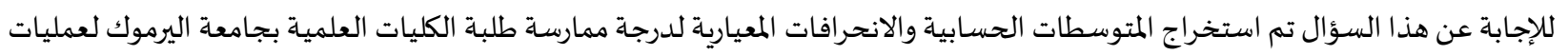
العلم، والجدول أدناه يوضح ذلك.

جدول (ع): المتوسطات الحسابية والانحر افات المعيارية لدرجة ممارسة طلبة الكليات العلمية بجامعة اليرموك لعمليات العلم مرتبة تنازلياً حسب العبات المتوسطات الحسابية

\begin{tabular}{|c|c|c|c|c|c|}
\hline المستوى & الالمعراف & المتوسط الحسابي & المجال & الرقم & الرتبة \\
\hline متوسط & אחדר,. & $r, \varepsilon$. & عمليات العلم المتكاملة & $r$ & 1 \\
\hline متوسط & (TוT & r, ז & عمليات العلم الأساسية & 1 & $r$ \\
\hline متوسط & .091 & $r, r q$ & مقياس عمليات العلم & & \\
\hline
\end{tabular}

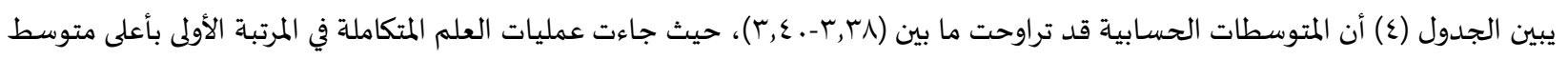

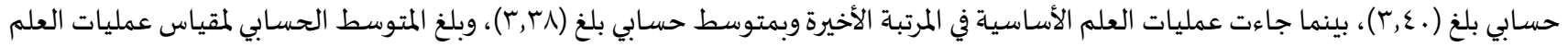

وقد تم حساب المتوسطات الحسابية والانحرافات المعيارية لتقديرات أفراد عينة الدراسة على مجالات كل من عمليات العلم الأسـاسية، عمليات العلم المتكاملة على حدة، حيث كانت على النحو التالي:

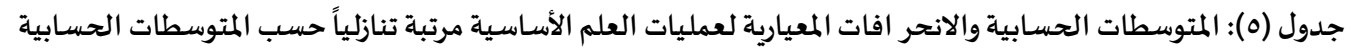

\begin{tabular}{|c|c|c|c|c|c|c|}
\hline المستوى & الانحراف المعياري & المتوسط الحسابي & & المجال & الرقم & الرتبة \\
\hline متوسط & rAT, T & $r, \leqslant 0$ & & الملاحظة & 1 & 1 \\
\hline متوسط & ., Vro & $r, \varepsilon r$ & & الاتصال & $v$ & $r$ \\
\hline متوسط &., $7 \times 1$ & $r, \varepsilon$. & & القياس & $r$ & $r$ \\
\hline متوسط & ., TAV & $r, r q$ & & الاستنتاج & $r$ & $\varepsilon$ \\
\hline متوسط & $\cdot, 717$ & $r, r v$ & & 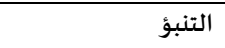 & 0 & 0 \\
\hline متوسط & . TAY & $r, r+4$ & & الاستدلال & $\varepsilon$ & 7 \\
\hline متوسط & . VVY & $r, r \varepsilon$ & المكانية & والزمانية & 7 & $v$ \\
\hline متوسط & (TוT) & $r, r_{\Lambda}$ & & عمليات العلم الأساسية & & \\
\hline
\end{tabular}

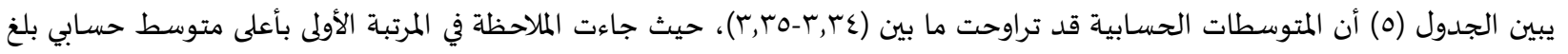

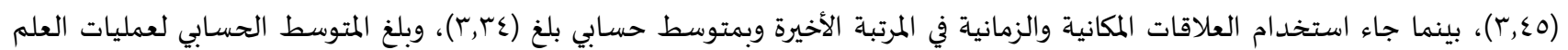

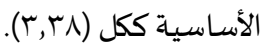


يوجد تدرج في درجة ممارسة عمليات العلم الأساسية والمتكاملة. فكانت عمليات العلم الأساسية أعلى من درجة ممارسة عمليات العلم المتكاملة، وجاءت عمليات العلم الأساسية (الملاحظة في المرتبة الأولى بأعلى متوسط حسابي (ب) بـ)، على اعتبار أن عملية الملاحظة من أسهل المهارات، والأكثر

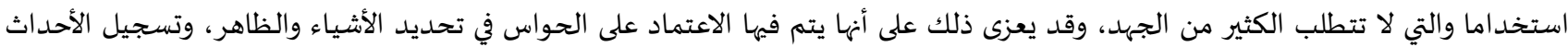
بالملاحظة المباشرة. وجاءت مهارة استخدام العلاقات الزمانية والمكانية في المرتبة الأخيرة بمتوسط حسابي بلغ (عب,r) وقد يعزى لعدم قدرة الطلبة على فيلى

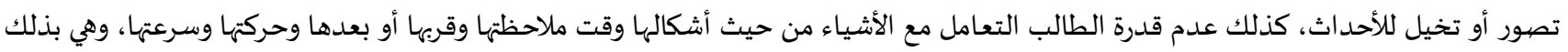

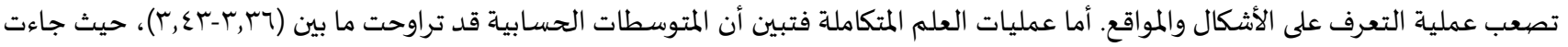

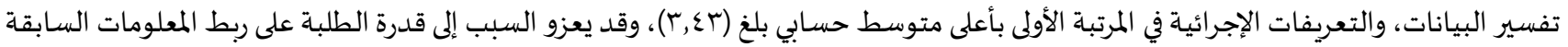

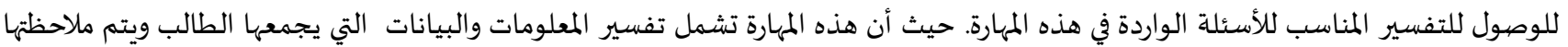
وتصنيفها, كذلك عدم قدرتهم على الاستقصاء لتفسير البيانات والنتائج التي تم التوصل إليها من خلال الخلفية العلمية لدى الطلبة وكذلك يقل

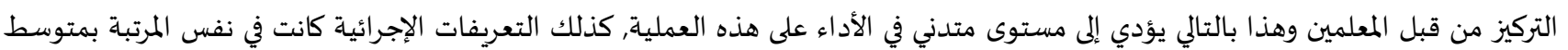
حسابي بلغ (r, r, وقد يعزو السبب في ذلك أن الطالب من خلال الحفظ والاستذكار يستطيع تحديد معنى المصطلح أو المفردة وبالتالي فهو يستطيع

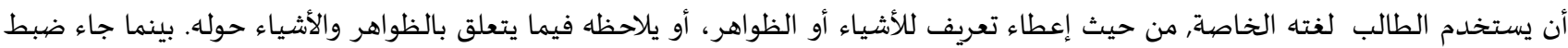

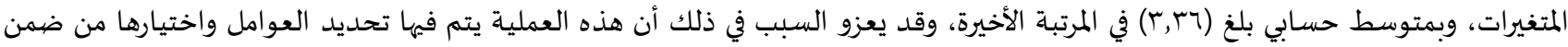

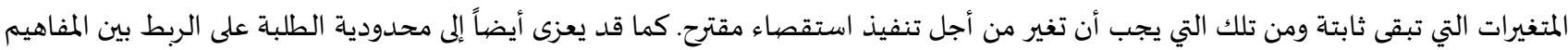

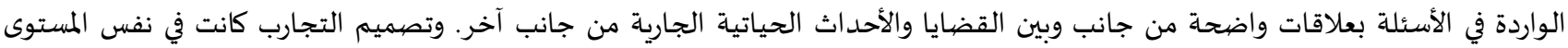

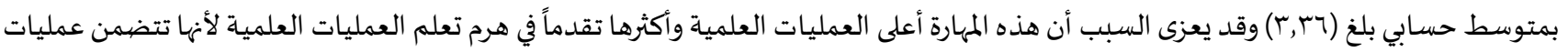
العلم جميعها. وهي تتطلب من الطالب قدرات وهي أن يمتلك جميع مهارات عمليات العلم، من حيث قدرة الطالب على إجراء التجارب العلمية بنجاح

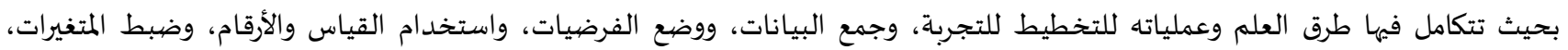

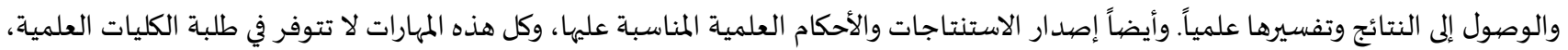

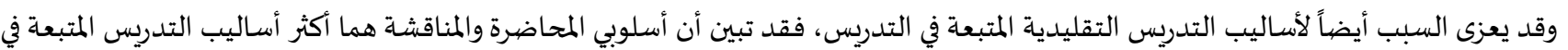

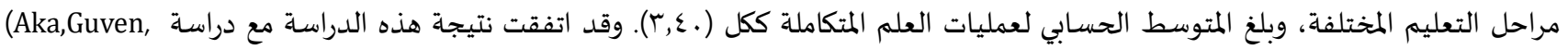

السؤال الثالث: هل توجد علاقة ارتباطية بين فهم طلبة الكليات العلمية لعمليات العلم وممارستهم لها؟ للإجابة عن هذا السؤال تم استخراج معامل ارتباط بيرسون بين فهم طلبة الكليات العلمية لعمليات العلم وممارستهم لها، والجدول (7) يوضح

جدول (7): ارتباط بيرسون للعلاقة بين فهم طلبة الكليات العلمية لعمليات العلم وممارستهم لها

\begin{tabular}{|c|c|c|c|c|c|c|c|c|c|}
\hline اختبار عمليات & الاتصال & استخدام العلاقات المكانية & التنبؤ & الاستدلال & الاستنتاج & القياس & الملاحظة & & \\
\hline **., \&Yr & $*^{* *} ., \leqslant 17$ & $*^{* *},\{01$ & **., \&.Y & **., \&TY & **. & **., $\leq Y \varepsilon$ & $\left.*_{* *}^{*}, \varepsilon r\right\}$ & J & الملاحظة \\
\hline **., ¿Аर & $* * ., \leqslant 91$ & **., $\leqslant 7$. & **., $\leqslant 94$ & $* * ., \leqslant \leqslant r$ & ${ }^{* *} ., \leq \wedge \Lambda$ & **., $\{\varepsilon$. & **., , . Y & J & الاستنتاج \\
\hline$* * ., 0 . \wedge$ & $* * ., 0.0$ & **., $\{१ \wedge$ & $*^{* *}, 0 . Y$ & $* * ., 011$ & **., 014 & **., $0 . \varepsilon$ & $*^{* *} .010$ & J & القياس \\
\hline${ }^{* *} ., 0 . V$ & **., $\{\wedge \uparrow$ & ${ }^{* *} ., \varepsilon \wedge \Lambda$ & **., & ${ }^{* *} ., \varepsilon \wedge \vee$ & ${ }^{* *} ., \leqslant V V$ & **., $\{\wedge १$ & **., $\leqslant 9$. & J & الاستدلال \\
\hline${ }^{* *}, 0.9$ & $* * ., 0.7$ & **., ¿८イ & **., $\leqslant 9 \vee$ & 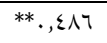 & **.,$\leqslant \wedge$. & **., $\{777$ & **.,$\leqslant 99$ & J & التنبؤ \\
\hline${ }^{* *} ., 01 r$ & **., OKT & 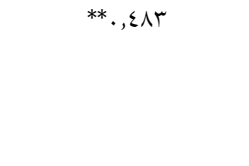 & ${ }^{* *}, 0 ., \varepsilon$ & ${ }^{* *} .,\{V \mid$ & **., $\leqslant \wedge 0$ & 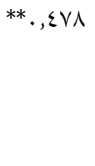 & **., OrI & J & المالعلاقات \\
\hline **., $\{\wedge q$ & ${ }^{* *} ., 019$ & **.,$\varepsilon \vee \wedge^{\prime}$ & ${ }^{* *}, 01$. & **., \&VY & ${ }^{* *} ., 0 . \wedge$ & $*^{* *}, \varepsilon \vee \vee 7$ & **.,or. & J & الاتصال \\
\hline${ }^{* *},, 009$ & ${ }^{* *} .$, TVO & ${ }^{* *},, q .$. & **., ז & ${ }^{* *} ., T \vee \varepsilon$ & **., 799 & ${ }^{* *},, 7 \wedge 1$ & ${ }^{* *}$, , Ү人 & , & عمليات العلم \\
\hline
\end{tabular}

*دالة إحصائيا عند مستوى الدلالة (0 . ..). //**دالة إحصائيا عند مستوى الدلالة ( . . .).

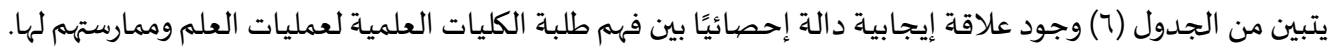


وقد تعزى هذه النتيجة إلى أنه كلما زادت نسبة الفهم عند طلبة الكليات العلمية لعمليات العلم لمهارات ومجالات معينة زادت ممارستهم لها، وكلما قل الفهم للمهارات في مجالات أخرى قلت الممارسـة فهها، كما أن طبيعة التخصصيات العلمية تعتمد على ممارسة عمليات العلم مما أدى إلى ظهور هذه النتيجة. وقد اتفقت نتيجة الدراسة مع دراسة عطية والحدابي (r . .r)، التي أظهرت وجود علاقة ارتباطية بين عمليات العلم وأداء الطلبة تبعاً لسنوات الدراسة الجامعية ولصالح المستوى الأعلى. السؤال الر ابع: هل تختلف درجة فهم عمليات العلم باختلاف السنة الدراسية، والتخصص، والمعدل التر اكمي؟ للإجابة عن هذا السؤال تم استخراج المتوسطات الحسابية والانحرافات المعيارية لدرجة فهم عمليات العلم حسب متغيرات السنة الدراسية، والتخصص، والمعدل التراكمي، والجدول أدناه يوضح ذلك.

جدول (V): المتوسطات الحسابية والانحر افات المعيارية لدرجة فهم عمليات العلم حسب متغيرات السنة الدراسية، والتخصص، والمعدل التر اكمي

\begin{tabular}{|c|c|c|c|c|c|}
\hline اختبار عمليات العلم & اختبار & اختبار & & & \\
\hline $7, Y \varepsilon$ & T, YT & $\varepsilon, \cdot T$ & المتوسط الحسابي & \multirow[t]{2}{*}{ سنة ثانية } & \multirow[t]{3}{*}{ السنة الدراسية } \\
\hline r,O人. & $1,1 \leqslant V$ & $r, . V T$ & الانحراف المعياري & & \\
\hline$\Lambda, r q$ & $r, \varepsilon V$ & 0,94 & المتوسط الحسابي & \multirow[t]{2}{*}{ سنة ثالثة } & \\
\hline$r, 91 T$ & $1, Y \Lambda$. & $r, \varepsilon \leqslant 1$ & الانحراف المعياري & & \\
\hline $9, r 7$ & $r, . \varepsilon$ & $7, r$ r & المتوسط الحسابي & \multirow[t]{2}{*}{ سنة رابعة } & \\
\hline$r, 0 \wedge \Lambda$ & $1,\{01$ & 1,19 & الانحراف المعياري & & \\
\hline$V, 7 \varepsilon$ & $r, 7$. & $0, . \varepsilon$ & المتوسط الحسابي & \multirow[t]{2}{*}{ سنة خامسة } & \\
\hline$r, 0 \leqslant 7$ & $1, \varepsilon T V$ & r,707 & الانحراف المعياري & & \\
\hline$v, 9 \varepsilon$ & T,OV & $0, \mathrm{ru}_{1}$ & المتوسط الحسابي & \multirow[t]{2}{*}{ طب } & \multirow[t]{2}{*}{ التخصص } \\
\hline$r, .10$ & $1,1 \wedge r$ & $r, \varepsilon \backslash \varepsilon$ & الانحراف المعياري & & \\
\hline$v, v i$ & $r, \leqslant 9$ & $0, r T$ & المتوسط الحسابي & \multirow[t]{2}{*}{ هندسة } & \\
\hline$r, I V T$ & 1,191 & T,OVT & الانحراف المعياري & & \\
\hline$\Lambda, Y \varepsilon$ & T, rV & $0, \Lambda \mathrm{V}$ & المتوسط الحسابي & \multirow[t]{2}{*}{ صيدلة } & \\
\hline$r, I \leqslant r$ & $1,\{\wedge \uparrow$ & r,or\& & الانحراف المعياري & & \\
\hline 9,10 & $r, Y$. & $7, .0$ & المتوسط الحسابي & \multirow[t]{2}{*}{ 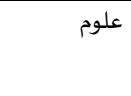 } & \\
\hline$r, \Lambda M \Lambda$ & l,V.r & 1,110 & الانحراف المعياري & & \\
\hline$r, 0$ T & $r, 09$ & $\varepsilon, q \mu$ & المتوسط الحسابي & \multirow[t]{2}{*}{ جيد } & \multirow[t]{4}{*}{ المعدل التراكي } \\
\hline$r$, rOI & I, TAY & T,ONT & الانحراف المعياري & & \\
\hline 9, ro & $r, V \varepsilon$ & 7,74 & المتوسط الحسابي & \multirow[t]{2}{*}{ جيد جدا } & \\
\hline T,OTA & l, rv. & $1,9 \pi$ & الانحراف المعياري & & \\
\hline $\mathrm{v}, \mathrm{VA}$ & r,or & 0, ro & المتوسط الحسابي & \multirow[t]{2}{*}{ ممتاز } & \\
\hline T,ATY & $1, r \wedge 7$ & r, Irq & الانحراف المعياري & & \\
\hline
\end{tabular}

يبين الجدول (V) تبايناً ظاهرياً في المتوسطات الحسابية والانحرافات المعيارية لدرجة فهم عمليات العلم بسبب اختلاف فئات متغيرات السنة الدراسية، والتخصص، والمعدل التراكمي.

ولبيان دلالة الفروق الإحصائية بين المتوسطات الحسابية تم استخدام تحليل التباين الثلاثي المتعدد على المجالات جدول (م). جدول (م): تحليل التباين الثلاثي المتعدد لأثر السنة الدراسية، والتخصص، والمعدل التر اكمي على مجالات عمليات العلم

\begin{tabular}{|c|c|c|c|c|c|c|}
\hline الإحصائية & قيمة ف & متوسط المربعات & درجات الحرية & مجموع المربعات & المجالات & مصدر التباين \\
\hline$\ldots$ & $\varepsilon \vee, \Upsilon \wedge \Gamma$ & Ylq,rrq & $r$ & $701, \ldots 9$ & عمليات العلم الأساسية & السنة الدراسية \\
\hline$\ldots$ & $1 r, \wedge \wedge 9$ & $T \varepsilon, \varepsilon r q$ & $r$ & $19 \%$, YAM & عمليات العلم الأساسية & التخصص \\
\hline \multirow[t]{5}{*}{$\ldots$} & $\{7, \cdot T$ & YIT,OYT & $r$ & $\varepsilon r V, .10$ & عمليات العلم الأساسية & المعدل التراكمي \\
\hline & & $\varepsilon, 7 r q$ & 991 & $\varepsilon 09 \mathrm{~V}, .1 \varepsilon$ & عمليات العلم الأساسية & الخطأ \\
\hline & & $1, \mathrm{VTr}$ & 991 & IVT.,OHA & عمليات العلم المتكاملة & \\
\hline & & & 999 & $09 \leqslant r, 97 \leqslant$ & عمليات العلم الأساسية & الكلي \\
\hline & & & 999 & $19.1, \mathrm{AV} \mid$ & عمليات العلم المتكاملة & \\
\hline
\end{tabular}


يتبين من الجدول (^) وجود فروق ذات دلالة إحصائية ( ه . . = م) تعزى لأثر السنة الدراسية في جميع المجالات لصالح السنة الدراسية الرابعة، وأيضاً وجود فروق ذات دلالة إحصائية ( 0 ., . a ) )عزى لأثر التخصص في جميع المجالات لصالج تخصص العلوم، وأيضاً وجود فروق ذات دلالة

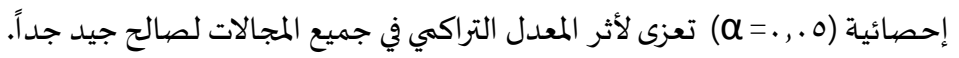
وقد يعزى ذلك، إلى أن أصحاب السنة الدراسية الرابعة تعرضوا إلى مواقف وخبرات وتجارب في مراحل حياتهم وفي المرحلة الدراسية بشكل أكبر من باقي السنوات الدراسية، وقد يعزى ذلك أيضاً إلى أصحاب تخصص العلوم، يوجد في موادهم الدراسية عمليات العلم مما أدى إلى اكتسابهم لهذه إنها

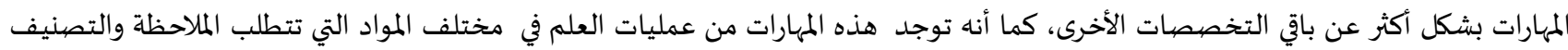
والقياس والاستنتاج بشكل أكبر عن باقي التخصصيات العلمية التي يكون جزئها الأكبر يعتمد على الحفظ والتلقين، وقد يعزى ذلك أيضاً أن أصحاب

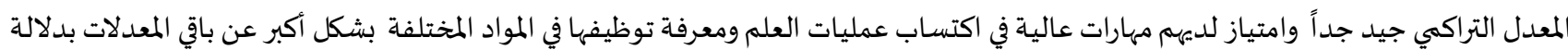

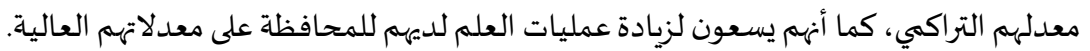

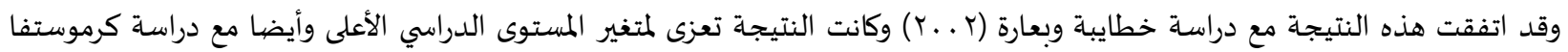

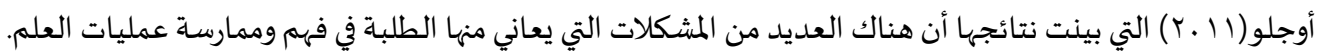

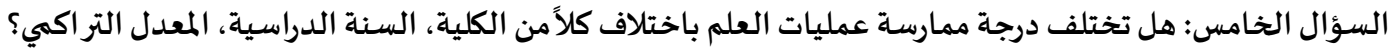

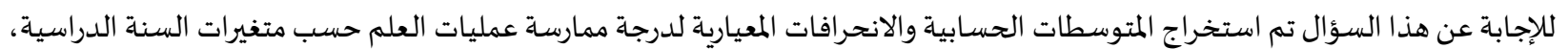
والتخصص، والمعدل التراكمي، والجدول (9) يوضح ذلك.

جدول(9): المتوسطات الحسابية والانحر افات المعيارية لدرجة ممارسة عمليات العلم حسب متغيرات السنة الدراسية، والتخصص، والمعدل التر اكمي

\begin{tabular}{|c|c|c|c|c|c|}
\hline مقياس عمليات العلم & عمليات العلم المتكاملة & عمليات العلم الأساسية & & & \\
\hline$r, \varepsilon \wedge$ & $r, \varepsilon r$ & $r, 0$. & المتوسط الحسابي & \multirow[t]{2}{*}{ سنة ثانية } & \multirow[t]{3}{*}{ السنة الدراسية } \\
\hline 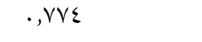 & ., V9V & .,var & الانحراف المعياري & & \\
\hline$r, r$. & $r, r)$ & $r, r q$ & المتوسط الحسابي & \multirow[t]{2}{*}{ سنة ثالثة } & \\
\hline 更, & אודו,. & .,700 & الانحراف المعياري & & \\
\hline$r, \varepsilon r$ & $r, \leq \varepsilon$ & $r, \varepsilon 1$ & المتوسط الحسابي & \multirow[t]{2}{*}{ سنة رابعة } & \\
\hline., 011 & .07T & . Orr & الانحراف المعياري & & \\
\hline$r, \xi 1$ & $r, \varepsilon r$ & $r, \varepsilon)$ & المتوسط الحسابي & \multirow[t]{2}{*}{ سنة خامسة } & \\
\hline •, $ะ 9 \mathrm{~V}$ &., 000 &., 0.4 & الانحراف المعياري & & \\
\hline$r, \varepsilon$. & $r, r u$ & $r, \varepsilon r$ & المتوسط الحسابي & \multirow[t]{2}{*}{ طب } & \multirow[t]{2}{*}{ التخصص } \\
\hline ., $\Sigma 9 \vee$ &., $0 Y$. &., 011 & الانحراف المعياري & & \\
\hline$r, r$. & $r, 19$ & $r, r)$ & المتوسط الحسابي & \multirow[t]{2}{*}{ هندسة } & \\
\hline .,OY1 & . OTY &., 071 & الانحراف المعياري & & \\
\hline$r, r q$ & $r, r q$ & $r, r q$ & المتوسط الحسابي & \multirow[t]{2}{*}{ صيدلة } & \\
\hline -,$\varepsilon 94$ &., $00 Y$ &., 0.4 & الانحراف المعياري & & \\
\hline$r, \wedge \varepsilon$ & $r, 9 \varepsilon$ & $r, \mathrm{Vq}$ & المتوسط الحسابي & \multirow[t]{2}{*}{ 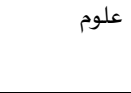 } & \\
\hline ( & $\cdot, \mathrm{V} \cdot \mathrm{A}$ & ., TVV & الانحراف المعياري & & \\
\hline$r, r$. & $r, r$. & $r, r)$ & المتوسط الحسابي & \multirow[t]{2}{*}{ جيد } & \multirow[t]{3}{*}{ المعدل التراكمي } \\
\hline., 000 &.,$T / Y$ &., $\mathrm{OVV}$ & الانحراف المعياري & & \\
\hline$r, r r$ & $r, r 7$ & $r, r T$ & المتوسط الحسابي & \multirow[t]{2}{*}{ جيد جداً } & \\
\hline., 0.1 &., 0 \% & . Ort & الانحراف المعياري & & \\
\hline r,vo & $r, v 7$ & $r, \mathrm{~V} \varepsilon$ & المتوسط الحسابي & \multirow[t]{2}{*}{ امتياز } & \\
\hline., $\mathrm{VIT}$ & , VYN & . VTr & الانحراف المعياري & & \\
\hline
\end{tabular}

يبين الجدول (9) تبايناً ظاهرياً في المتوسطات الحسابية والانحرافات المعيارية لدرجة ممارسة عمليات العلم بسبب اختلاف فئات متغيرات السنة الدراسية، والتخصص، والمعدل التراكمي. ولبيان دلالة الفروق الإحصائية بين المتوسطات الحسابية تم استخدام تحليل التباين الثلاثي المتعدد على المجالات والجدول (ـ ا ) يوضح ذلك. 


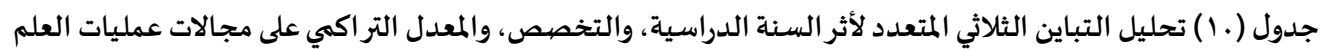

\begin{tabular}{|c|c|c|c|c|c|c|}
\hline الإحصائية & قيمة ف & متوسط المربعات & درجات الحرية & مجموع المربعات & المجالات & مصدر التباين \\
\hline .,人 ^ &.,$Y \leqslant 1$ &.,. $\mathrm{VV}$ & $r$ & . & عمليات العلم الأساسية & السنة الدراسية \\
\hline.,$\ldots$ & $r T, r \cdot T$ & $1 ., 019$ & $r$ & rI,V\V & عمليات العلم الأساسية & التخصص \\
\hline ., $\ldots$ & $19, r \wedge \varepsilon$ & $7,17 \varepsilon$ & r & IT,TYV & عمليات العلم الأساسية & المعدل التراكمي \\
\hline & & . & 991 & $r 10,1 \cdot V$ & عمليات العلم الأساسية & الخطأ \\
\hline & &.,$r \cdot 9$ & 991 & $r .7,100$ & عمليات العلم المتكاملة & \\
\hline & & & 999 & rVo,114 & عمليات العلم الأساسية & الكلي \\
\hline & & & 999 & $\{\ldots,\{7\}$ & عمليات العلم المتكاملة & \\
\hline
\end{tabular}

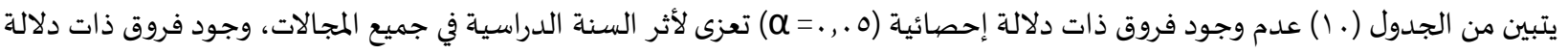

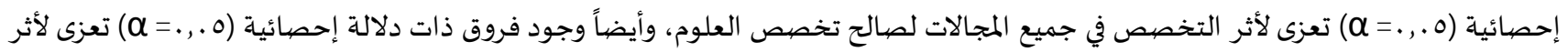

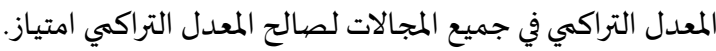

وقد يعزى ذلك إلى أن أصحاب السنوات الدراسية بالكليات العلمية يمارسون مهارات عمليات العلم بالعمل والممارسة وهذا يعطي الطالب خبرة كاملة تحفزه على التفكير, وبالتالي فهو يمتلك مهارات عديدة كالملاحظة والتصنيف والقياس أي امتلاك عمليات العلم وممارستها, بنفس النسبة و بشكل أكبر من غيرهم من التخصصيات الأخرى، على عكس التخصصيات الأخرى الذين يهملون هذه المهارات في المراحل المتقدمة من الحياة الجامعية ويفقدون

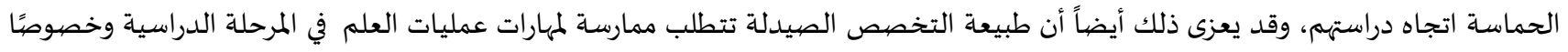

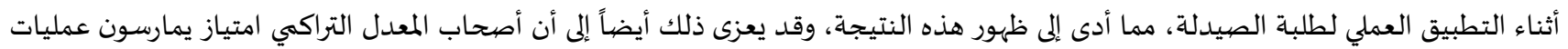

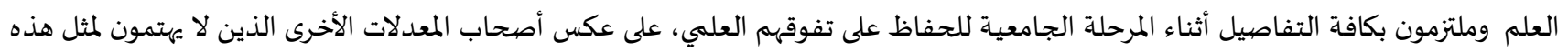

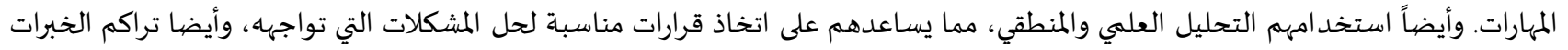

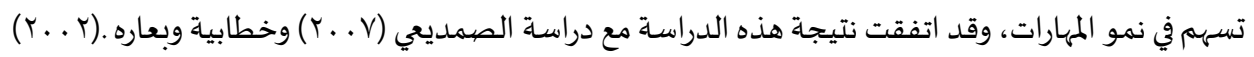

وفي ضوء نتائج الدراسـة، يوصي الباحثين بالآتي:

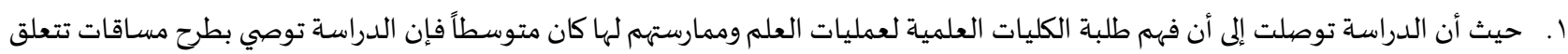

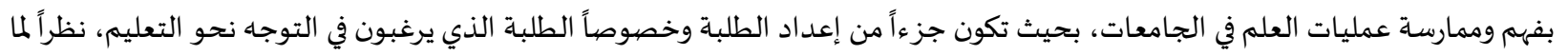

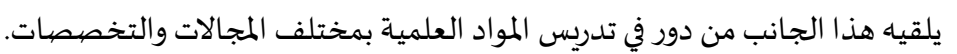

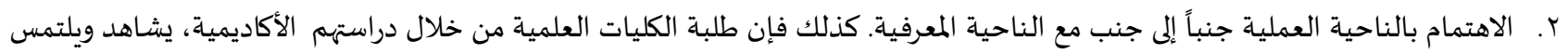
باستمرار المهارات العلمية من خلال ممارساة المنهج التجريبي والتحليل المنطقي، والتفكير العلمي وأيضاً من خلاليال استناده إلى الأدلة العلمياة في

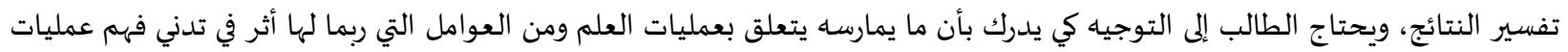

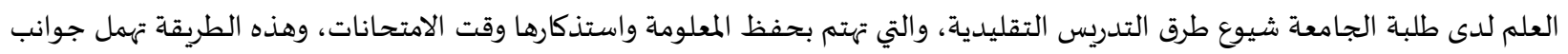

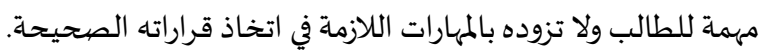
r. إجراء المزيد من البحث والاستقصاء في موضوع مهارات عمليات العلم وتناول عوامل أخرى تؤثر في رفع مستوى عمليات العلم كالدافعية، والاتجاهات، والميول. ع. ضرورة اهتمام القائمين على المقررات الدراسية في الجامعات بتضمين عمليات العلم، وإدراجها مثل مهارة الملاحظة، والقياس، والاستدلال،

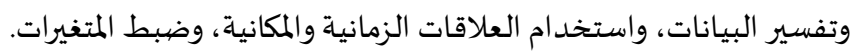
0 . إجراء دراسة مشابهة للدراسة الحالية لمعرفة مدى تطور فهم مهارات عمليات العلم ومدى ممارستهم لها.

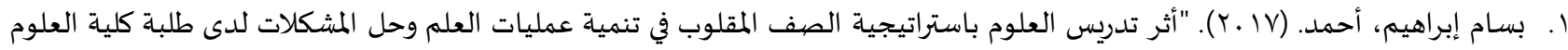
التربوية في الأردن". كلية العلوم التربوية الجامعية الأونروا عمان- المملكة الأردنية الهاشمية. مجلة باستراتية اتحاد الجامعات العربية للبحوث في في التعليم

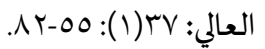

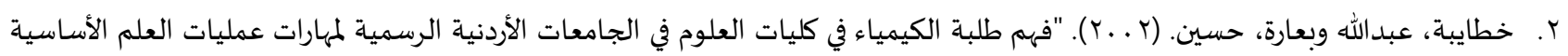

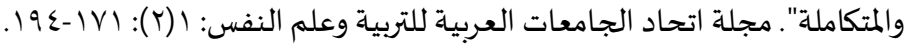




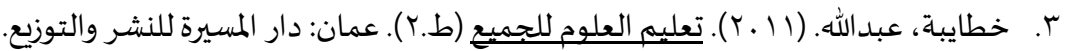

$$
\begin{aligned}
& \text { ع. الخليلي، خليل وحيدر، عبد اللطيف و يونس، محمد. (1997) . تدريس العلوم في مراحل التعليم العام. دار القلم:الإمارات. }
\end{aligned}
$$

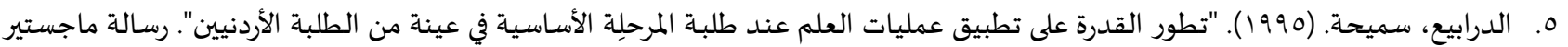

$$
\text { غير منشورة كلية الدراسات العليا. الجامعة الأردنية. الأردن. }
$$

7.

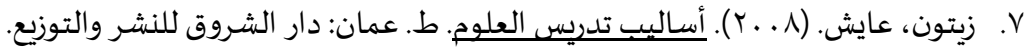

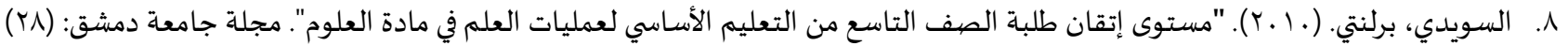

$$
\text { دمشق. سوريا. }
$$

9. الصعيمدي، هبة. (V . . r). "العلاقة بين مهارات العمليات العلمية والتحصيل في مادة الفيزياء لدى طلبة الصف الخامس العلمي". مجلة التربية

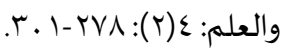

• ا ـ عبيد ات، ذوقان وآخرون. ( (1991). البحث العلمي مفهومه وأدواته وأساليبيه. عمان. دار الفكر للطباعة والنشر.

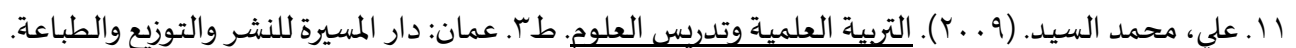

r ا. المركز الوطني لتطوير المناهج.(19 ـ (1). الإطار العام للنتاجات ومؤشرات مناهج العلوم في الأردن. عمان: الأردن.

ثانياً: المراجع الأجنبية

[1] Aydogdu, B., Erkol, M., \& Erten, N. (2014). "The investigation of science process skills of elementary school teachers in terms of some variables: Perspectives from Turkey. Asia-Pacific Forum on". Science Learning and Teaching, 15: $245-273$.

[2] Carin, S.A \& Evans, J.M, (1980). Sciencing Central Michigan UN 2ed.

[3] Lekka - Kowalika, A. (2009). "Why science cannot be value- free: understanding the rationality and responsibility of science". Science and Engineering Ethics, 16(1): 33-41. https://doi.org/10.1007/s11948-009-9128-3.

[4] Martin, D.I. (1997). "Elementary Science Methods”. San Francisco: Delmar Publishers.

[5] Northcote, T. (2005). "The educational beliefs a group of university teachers and their students: identification, exploration and comparisons". PhD Theses, Edith Cowan University.

[6] Sadler, T. \& Zeidler, D. (2005). "Patterns of informal reasoning in the context of Socioscientific decision making". Journal of Research in Science Teaching, 40 (4): 369-392.

[7] Zaytoon, A. M. (2010). “Contemporary Global Trends in Science Curriculum and Instruction”. Amman: Dar Al Shorouk for Publishing and Distribution. 
المجلة الدولية للدراسـات التربوية والنفسية

International Journal of Educational \& Psychological Studies (EPS)

Journal Homepage: https://www.refaad.com/views/EPSR/Home.aspx

www.refaad.com

ISSN: 2520-4149 (Online) 2520-4130 (Print)

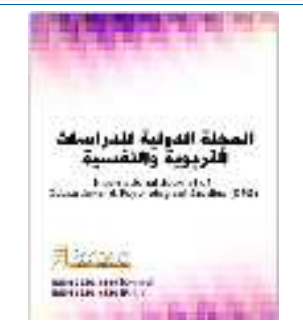

\title{
The degree to which students of scientific colleges at Yarmouk University understand
} the science process skills of reason and their practice in light of some variables

\author{
${ }^{1}$ Rimh Omar Maatouq, ${ }^{2}$ Abdullah Muhammad Khataybah, ${ }^{3}$ Ibtisam Qasim Rababaa \\ ${ }^{1}$ Researcher at the College of Education, Department of Curricula and Methods of Teaching Sciences, \\ Yarmouk University, Jordan \\ 2Professor at the College of Education, Department of Curricula and Methods of Teaching Sciences, \\ Yarmouk University, Jordan \\ ${ }^{3}$ Associate Professor, College of Education, Curriculum and Methods of Teaching Sciences, Yarmouk University, \\ Jordan \\ 1'Kulaep_hn@yahoo.com
}

\begin{abstract}
Received : 6/2/2020 Revised : 20/2/2020 Accepted : 10/3/2020 DOI : https://doi.org/10.31559/EPS2021.9.1.1
\end{abstract}
Abstract: The study aimed at investigate the impact of students of scientific colleges at Yarmouk University (Jordan) understanding Science Process skills, sample was formed The study is from students of scientific colleges at Yarmouk was chosen in the stratified random way consisted of 1000) male and female students The results of the study showed that the relative importance ranged between (29\% -55\%), It also showed a high degree of understanding of the science processes of students, and showed a positive statistically significant relationship between the understanding of students of scientific colleges and processes of science. It also showed the existence of differences due to the understanding of the science processes attributable to the impact of the school year in favor of the fifth school year, and also the presence of differences attributable to the impact of specialization in all fields in favor of the science specialization, and also the presence of differences attributable to the effect of the cumulative average in all fields in favor of a very good, and also showed that there were no differences in the practice Science operations are attributable to the impact of the school year, and the presence of differences attributed to the impact of specialization in all fields in favor of the specialty of pharmacy, and also the presence of differences due to the effect of the cumulative average in all fields in favor of the cumulative average privilege. The study recommended attention to the practical aspect, along with the cognitive aspect. Likewise, students of scientific colleges through their academic studies constantly watch and seek scientific skills through practicing the experimental approach, logical analysis, and scientific thinking, and also by relying on scientific evidence to interpret the results.

Keywords: Yarmouk University; students of scientific colleges; Science Process skills; understanding and practicing students.

\section{References:}

[1] 'bydat, Dwqan Wakhrwn. (1998). Albhth Al'Imy Mfhwmh Wadwath Wasalybh. 'man. Dar Alfkr Lltba'h Walnshr.

[2] 'ly, Mhmd Alsyd. (2009). Altrbyh Al'Imyh Wtdrys Al'lwm. T3. 'man: Dar Almsyrh Llnshr Waltwzy' Waltba'h.

[3] Bsam Ebrahym, Ahmd. (2017). "Athr Tdrys Al'lwm Bastratyjyh Alsf Almqlwb Fy Tnmyt 'mlyat Al'lm Whl Almshklat Lda Tlbt Klyt Al'lwm Altrbwyh Fy Alardn". Klyt Al'lwm Altrbwyh Aljam'yh Alawnrwa 'man- Almmlkh Alardnyh Alhashmyh. Mjlt Athad Aljam'at Al'rbyh Llbhwth Fy Alt'lym Al'aly: 37(1): 55-82.

[4] Aldraby', Smyhh. (1995). "Ttwr Alqdrh 'la Ttbyq 'mlyat Al'Im 'nd Tlbh Almrhlh Alasasyh Fy 'ynh Mn Altlbt Alardnyyn". Rsalt Majstyr Ghyr Mnshwrh Klyt Aldrasat Al'lya. Aljam'h Alardnyh. Alardn.

[5] Khtaybh, 'bdallh Wb'earh, Hsyn. (2002). "Fhm Tlbt Alkymya' Fy Klyat Al'lwm Fy Aljam'at Alardnyh Alrsmyh Lmharat 'mlyat Al'Im Alasasyh Walmtkamlh". Mjlt Athad Aljam'at Al'rbyh Lltrbyh W'lm Alnfs: 1(2): 171-194.

[6] Khtaybh, 'bdallh. (2011). T'lym Al'elwm Lljmy' (T.2). 'man: Dar Almsyrh Llnshr Waltwzy'.

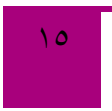


[7] Alkhlyly, Khlyl Whydr, 'bdalltyf W Ywns, Mhmd. (1996). Tdrys Al'lwm Fy Mrahl Alt'lym Al'am. Dar Alqlm: Alemarat.

[8] Almrkz Alwtny Lttwyr Almnahj.(2019). Aletar Al'am Llntajat Wm'shrat Mnahj Al'lwm Fy Alardn. 'man: Alardn.

[9] Als'ymdy, Hbh. (2007). "Al'laqh Byn Mharat Al'mlyat Al'lmyh Walthsyl Fy Madh Alfyzya' Lda Tlbh Alsf Alkhams Al'lmy". Mjlt Altrbyh Wal'lm: 4(2): 278-301.

[10] Alswydy, Brlnty. (2010). "Mstwa Etqan Tlbt Alsf Altas' Mn Alt'lym Alasasy L'mlyat Al'lm Fy Madh Al'lwm". Mjlt Jam't Dmshq: (28) Dmshq. Swrya.

[11] Zytwn, 'aysh. (2012). Alatjahat Al'almyh Alm'asrh Fy Mnahj Al'lwm Wtdrysha. 'man: Dar Alshrwq Llnshr Waltwzy'.

[12] Zytwn, 'aysh. (2008). Asalyb Tdrys Al'lwm. T. 'man: Dar Alshrwq Llnshr Waltwzy'. 